\title{
Trabeculectomy: a retrospective long-term follow-up of 444 cases
}

\author{
K. B. MILLS \\ From the Manchester Royal Eye Hospital, Oxford Road, Manchester M13 9WH
}

SUMMARY The results of the surgical procedure of trabeculectomy, as performed by the staff of the Manchester Royal Eye Hospital from 1974 to 1979 inclusive on 356 patients (444 eyes) are presented, with particular emphasis not only on intraocular pressure control but on operative and postoperative long-term complications. Its position in the surgical treatment of glaucoma is confirmed, but the attendant surgical and long-term side effects associated with trabeculectomy appear to be more widespread and problematical than previous reports would suggest.

Trabeculectomy, introduced by Cairns ${ }^{1}$ and modified by Watson, ${ }^{2}$ has become the favoured procedure for the surgical management of various types of glaucoma. Its success in controlling the intraocular pressure without many of the serious operative and postoperative complications associated with previous drainage procedures has been well demonstrated by many authors..$^{3-8}$ Although the surgical technique was originally designed to work by allowing aqueous to gain access to the cut ends of Schlemm's canal, several authors have shown that it appears to be effective by simple fistulisation to a subconjunctiva! drainage bleb. ${ }^{3910}$

As a consequence of many encouraging reports trabeculectomy is assuming increasing importance in the management of glaucoma. It is often no longer considered as a second-line treatment for use when medical treatment fails to control the glaucomatous process, but rather as a serious contender for use as the initial management of the disease. It is with this development in mind that a retrospective study of 444 eyes undergoing trabeculectomy was undertaken. Particular emphasis is placed not only on the control of intraocular pressure but also on the accompanying short and long-term drawbacks of this procedure.

\section{Materials and methods}

All patients undergoing trabeculectomy at the Manchester Royal Eye Hospital from 1974 to 1979 inclusive, and who were available for follow-up, were studied. A total of 356 patients (444 eyes) were included in the study. They were divided into various glaucomatous groups based on the preoperative clinical and gonioscopic appearance (Table 1). Four groups accounted for $90 \%$ of cases (Table 1): chronic simple open angle, acute closed angle, compound (narrow angle and chronic angle-closure), and combined (trabeculectomy and cataract extraction).

\section{TECHNIQUE}

The surgical procedure is based on that described by Watson. ${ }^{2}$ Most of the operations were performed by the consultant staff and senior registrars of the above hospital. A small percentage were carried out by the junior staff of registrar status.

Most of the surgery was performed with the help of magnification. The variations in technique that occurred were mainly twofold. Firstly, the conjunctival incision was usually made well posteriorily to the limbus near the superior rectus insertion; occasionally it was made more anteriorily. Secondly, the number of virgin-silk sutures applied to the scleral

Table 1 Breakdown of 444 eyes into glaucoma groups as described in text

\begin{tabular}{lrrrrrr}
\hline Glaucomatype & $\begin{array}{l}\text { Patient } \\
\text { nos. }\end{array}$ & $\begin{array}{l}\text { Eves } \\
\text { total }\end{array}$ & $\begin{array}{l}\text { \% of } \\
\text { tolears }\end{array}$ \\
\hline Chronic simple & 154 & 220 & $49 \cdot 7$ & 55 & 99 & $67 \cdot 2$ \\
Acute closed angle & 78 & 81 & $18 \cdot 3$ & 53 & 25 & $65 \cdot 8$ \\
Compound & 56 & 66 & $14 \cdot 9$ & 32 & 25 & $66 \cdot 5$ \\
Combined procedure & 27 & 34 & $7 \cdot 4$ & 17 & 10 & $74 \cdot 6$ \\
Secondary & 15 & 16 & $3 \cdot 6$ & 4 & 11 & $37 \cdot 4$ \\
Open angle with & & & & & & \\
pseudoexfoliation & 14 & 14 & $3 \cdot 2$ & 6 & 8 & $67 \cdot 4$ \\
Rubeotic & 7 & 8 & $1 \cdot 8$ & 3 & 4 & $52 \cdot 1$ \\
Aphakic & 5 & 5 & $1 \cdot 1$ & 4 & 1 & $61 \cdot 8$ \\
\hline
\end{tabular}




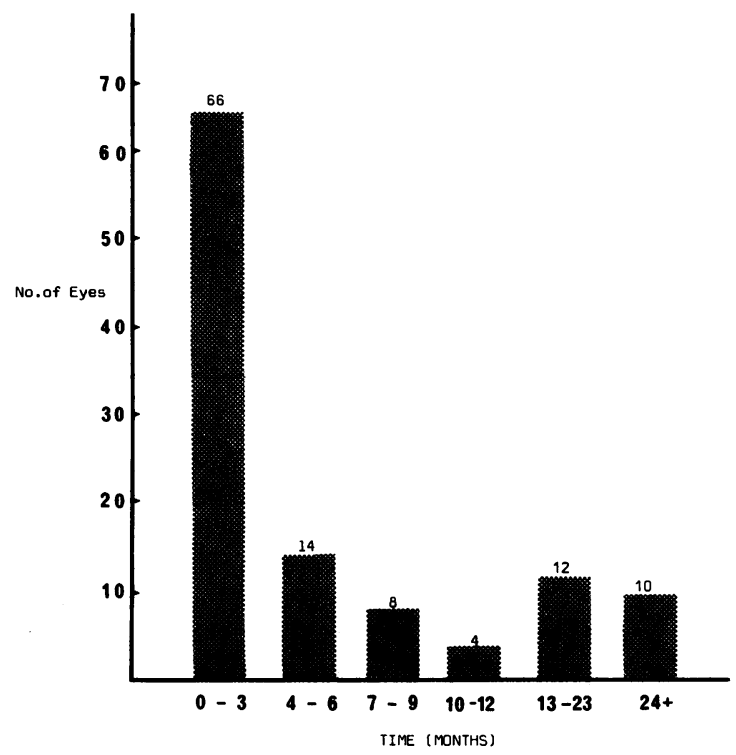

Fig. 1 Histogram showing number of eyes requiring postoperative medication and the time postoperatively when this began (from a total of 415 eyes)

flap varied with different surgeons from 2 to 4 . A minority of eyes received post-surgical subconjunctival antibiotics (either gentamicin or soframycin).

\section{Results}

Table 2 gives analysis of the success of the procedure in terms of control of intraocular pressure (defined as an IOP $<21 \mathrm{mmHg}$ ), with or without additional medication and for each glaucoma type. The intraocular pressure reading used for this analysis is that recorded at the latest clinic attendance.

Eyes requiring postoperative medication in an attempt to normalise intraocular pressure, with the

Table 2 Percentage of eyes controlled with or without treatment, or uncontrolled: control is taken as an $I O P<21 \mathrm{mmHg}$

\begin{tabular}{lllll}
\hline Glaucoma type & $\begin{array}{l}\text { Control } \\
\text { without }\end{array}$ & $\begin{array}{l}\text { Control } \\
\text { with }\end{array}$ & $\begin{array}{l}\text { Control } \\
\text { without and } \\
\text { with }\end{array}$ & Uncontrolled \\
\hline Chronic simple & $73 \cdot 4$ & $13 \cdot 5$ & 86.9 & $13 \cdot 1$ \\
Acute closed angle & $74 \cdot 1$ & $16 \cdot 1$ & $90 \cdot 2$ & $9 \cdot 8$ \\
Compound & $68 \cdot 2$ & $18 \cdot 2$ & $86 \cdot 4$ & $13 \cdot 6$ \\
Combined procedure & $47 \cdot 2$ & $38 \cdot 9$ & $86 \cdot 1$ & $13 \cdot 9$ \\
Secondary & $37 \cdot 5$ & $12 \cdot 5$ & 50 & 50 \\
Open angle with & & $7 \cdot 1$ & $71 \cdot 3$ & $28 \cdot 6$ \\
pseudoexfoliation & $64 \cdot 2$ & $7 \cdot 1$ & $12 \cdot 5$ & $87 \cdot 5$ \\
Rubeotic & $12 \cdot 5$ & 0 & 75 & 25 \\
Aphakic & 50 & 25 & & \\
\hline
\end{tabular}

Table 3 Distribution of IOP (taken at latest clinic attendance) for chronic, acute closed-angle, compound, combined, and pseudoexfoliative glaucoma (total 415 eyes)

\begin{tabular}{lllllll}
\hline & \multicolumn{7}{l}{ IOP reading $\mathrm{mmHg}$} \\
\cline { 2 - 7 } & $<10$ & $11-1.5$ & $16-20$ & $21-2.5$ & $26-30$ & $>30$ \\
\hline $\begin{array}{l}\text { Number of eyes } \\
\text { \% of total }\end{array}$ & 41 & 122 & 195 & 32 & 11 & 14 \\
\hline
\end{tabular}

time at which this was first instituted, are shown in the histogram in Fig. 1 (from a total of 415 eyes). Rubeotic, aphakic, and secondary glaucomas are omitted from this evaluation because their numbers are too small to be meaningful (rubeotic and aphakic) or they represent an ad hoc mixture of uncommon glaucomas (secondary). 124 eyes required additional medication $(30.0 \%)$ at a mean onset of 8.3 months postoperatively. Only 35 eyes required treatment after a postoperative time of 6 months or more. Hence 89 eyes $(71.8 \%$ of the total requiring medication) required the antiglaucoma medication in the first 6 months (mean 1.9 months postoperatively).

The distribution of IOP readings taken at the latest clinic attendance for all eyes excluding rubeotic, aphakic, and secondary (total 415), whether controlled with treatment or without, or uncontrolled, is shown in Table 3 and expressed diagramatically in Fig. 2.

The relationship between IOP and time of follow-

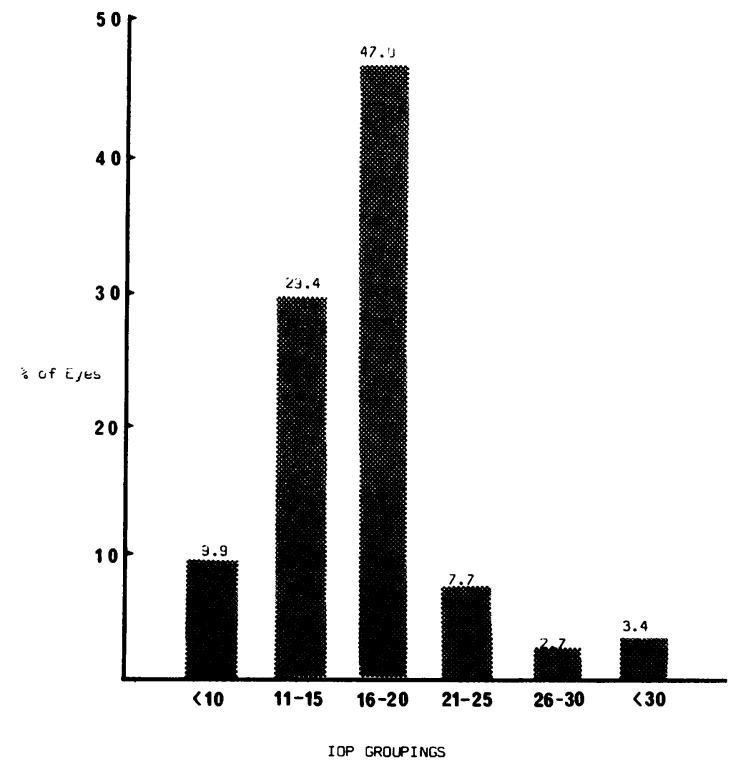

Fig. 2 Histogram showing distribution of IOPs. Figures used are taken from total column in Table 3 


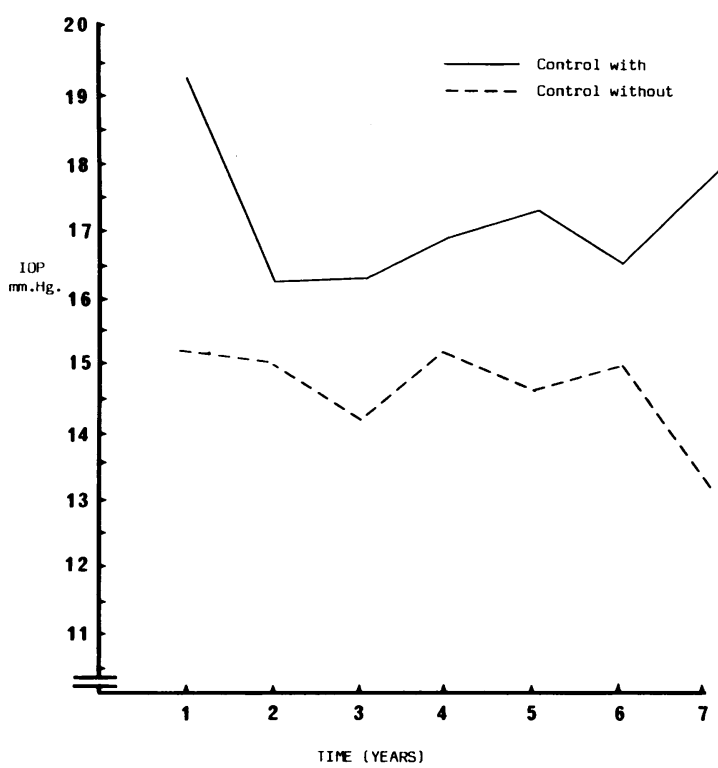

Fig. 3 The intraocular pressure levels with lapse of time for eves controlled with and without medication in chronic, acute closed-angle, and compound glaucoma (367 eyes)

up is shown graphically in Fig. 3. The figures are taken from Table 4, which shows the duration of follow-up and mean IOP readings, with or without treatment, for chronic, acute closed-angle, and compound glaucoma (total 367 eyes).

Table 5 gives a full list of short- and long-term complications of this procedure in 435 eyes. Hyphaemas lasting less than 5 days are excluded. Loss of visual acuity is included if this was more than 2 Snellen lines with correction. Further surgery includes either a further trabeculectomy (or drainage procedure) or surgery necessitated as a direct consequence of the trabeculectomy (i.e., for malignant glaucoma or the removal of a rapidly swollen lens). Later removal of a cataract is not included.

The percentage of eyes with and without short- or long-term complications (as shown in Table 5) for the

Table 4 Number of eyes at yearly follow-up (for those controlled without and with medication) with corresponding mean IOPs ( $\mathrm{mmHg}$ ) for chronic, acute closed-angle, and compound glaucoma (total 367 eyes)

\begin{tabular}{|c|c|c|c|c|c|c|c|c|}
\hline \multicolumn{2}{|c|}{ Follow-up (years) } & \multirow{2}{*}{$\frac{1.0}{34}$} & \multirow{2}{*}{$\frac{2 \cdot 0}{44}$} & \multirow{2}{*}{$\begin{array}{l}3 \cdot 0 \\
49\end{array}$} & \multirow{2}{*}{$\frac{4 \cdot 0}{55}$} & \multirow{2}{*}{$\frac{5 \cdot 0}{44}$} & \multirow{2}{*}{$\frac{6 \cdot 0}{28}$} & \multirow{2}{*}{$\frac{7 \cdot 0}{10}$} \\
\hline $\begin{array}{l}\text { Controlled } \\
\text { without }\end{array}$ & $\begin{array}{l}\text { No. } \\
\text { IOP }\end{array}$ & & & & & & & \\
\hline & $\mathrm{mmHg}$ & $15 \cdot 4$ & $15 \cdot 1$ & $14 \cdot 4$ & $15 \cdot 3$ & $15 \cdot 1$ & $15 \cdot 2$ & $13 \cdot 3$ \\
\hline \multirow[t]{2}{*}{$\begin{array}{l}\text { Controlled } \\
\text { with }\end{array}$} & $\begin{array}{l}\text { No. } \\
\text { IOP }\end{array}$ & 2 & 9 & 11 & 13 & 15 & 5 & 2 \\
\hline & $\mathrm{mmHg}$ & $18 \cdot 5$ & $16 \cdot 2$ & $16 \cdot 2$ & $17 \cdot 0$ & $17 \cdot 0$ & $16 \cdot 5$ & $17 \cdot 5$ \\
\hline
\end{tabular}

Table 5 A comprehensive list of short- and long-term complications of trabeculectomy in 435 eyes (rubeotic glaucoma excluded)

\begin{tabular}{lrllrr}
\hline Complication & No. $(\%)$ & & Complication & No. (\%) \\
\cline { 1 - 2 } \cline { 5 - 6 } Hyphaema 5/7 & $30(6 \cdot 9)$ & & Retinal detachment & $1(0 \cdot 2)$ \\
Shallow or flat AC & $57(13 \cdot 1)$ & & Severe uveitis & $4(0 \cdot 8)$ \\
Resuturing conjunctiva & $7(1 \cdot 6)$ & & Decrease visual acuity $>2$ lines & $66(15 \cdot 2)$ \\
Reformation of AC & $7(1 \cdot 6)$ & Endophthalmitis & $2(0 \cdot 5)$ \\
Uveal prolapse & $2(0 \cdot 5)$ & Herpetic keratitis & $1(0 \cdot 2)$ \\
Choroidal detachment & 23 & $(5 \cdot 3)$ & Enucleation & $1(0 \cdot 2)$ \\
Malignant glaucoma & 3 & $(0 \cdot 7)$ & Further surgery & $27(6 \cdot 2)$ \\
\cline { 1 - 1 } & & & &
\end{tabular}

$\mathrm{AC}=$ anterior chamber

4 numerically largest groups of glaucoma is shown in Table $6.59 .9 \%$ of eyes controlled with or without treatment are thus free of such complications. $6.2 \%$ of eyes are uncontrolled but have no complications. The percentage of eyes, therefore, showing one or more complications as shown in Table 5 is $33.9 \%$.

Table 6 Percentage of eyes with chronic, acute, compound combined glaucoma (401 eyes) subjected to one or more complications shown in Table 5.

\begin{tabular}{|c|c|c|c|c|c|c|c|}
\hline \multicolumn{4}{|c|}{ No complications } & \multicolumn{4}{|c|}{ Complications } \\
\hline $\begin{array}{l}\text { Control } \\
\text { without }\end{array}$ & $\begin{array}{l}\text { Control } \\
\text { with }\end{array}$ & $\begin{array}{l}\text { Uncon- } \\
\text { trolled }\end{array}$ & Total & $\begin{array}{l}\text { Control } \\
\text { without }\end{array}$ & $\begin{array}{l}\text { Control } \\
\text { with }\end{array}$ & $\begin{array}{l}\text { Uncon- } \\
\text { trolled }\end{array}$ & Total \\
\hline $48 \cdot 1$ & $11 \cdot 8$ & $6 \cdot 2$ & $66 \cdot 1$ & $21 \cdot 9$ & $7 \cdot 0$ & $5 \cdot 0$ & $33 \cdot 9$ \\
\hline
\end{tabular}

Table 7 shows the number of eyes having surgical problems (as shown in Table 5), for the major glaucoma groups, with particular reference to the control of intraocular pressure postoperatively.

Table 8 shows the severity of visual loss secondary to cataract formation with regard to time elapsed postoperatively in eyes with chronic, compound, pseudoexfoliative, and acute closed-angle glaucoma (381 eyes). $45 \cdot 2 \%$ of 62 eyes so affected showed serious visual loss within the first 6 months postoperatively. Of these 28 eyes $17(60 \cdot 7 \%)$ were associated with shallow/flat anterior chamber post-

Table 7 Number of eyes (percentage in brackets) for the glaucoma groups shown having surgical problems (as described in Table 5) in relation to the control of postoperative intraocular pressure

\begin{tabular}{lccc}
\hline Glaucoma trpe & $\begin{array}{l}\text { Control } \\
\text { without }\end{array}$ & $\begin{array}{l}\text { Control } \\
\text { with }\end{array}$ & Uncontrolled \\
\hline Open angle & $40(24 \cdot 8)$ & $11(38 \cdot 0)$ & $9(31)$ \\
Acute closed angle & $16(26 \cdot 7)$ & $1(7 \cdot 7)$ & $4(66 \cdot 7)$ \\
Compound & $12(26 \cdot 7)$ & $2(16 \cdot 7)$ & $2(22 \cdot 2)$ \\
Combined & $3(18 \cdot 8)$ & $1(5 \cdot 9)$ & $2(100)$ \\
Total & $71(25 \cdot 3)$ & $15(20)$ & $15(35 \cdot 6)$ \\
\hline
\end{tabular}


Table 8 Severity of visual loss secondary formation in 62 eyes (from total of 381 eyes)

\begin{tabular}{|c|c|c|c|c|c|}
\hline \multirow[t]{2}{*}{ Loss of acuity } & \multicolumn{5}{|c|}{ Postoperative follow-lip } \\
\hline & $<6 / 12$ & $\begin{array}{l}6 / 12- \\
12 / 12\end{array}$ & $\begin{array}{l}1,3 / 12- \\
24 / 12\end{array}$ & $\begin{array}{l}25 / 12 \\
36 / 12\end{array}$ & $\begin{array}{l}37 / 12 \\
48 / 12\end{array}$ \\
\hline$-0 \cdot 3$ & 9 & 2 & 2 & 3 & 2 \\
\hline$-0 \cdot 4$ & 8 & 1 & 3 & 0 & 0 \\
\hline$-0 \cdot 5$ & 2 & 2 & 1 & 2 & 1 \\
\hline$-0 \cdot 6$ & 4 & 3 & 4 & 1 & 1 \\
\hline$-0 \cdot 7$ & 3 & 0 & 2 & 1 & 0 \\
\hline$-0 \cdot 8$ & 1 & 0 & 0 & 1 & 0 \\
\hline$>-0.8$ & 1 & 1 & 0 & 0 & 1 \\
\hline
\end{tabular}

operatively, 2 required resuturing of conjunctival wound, and 2 had the anterior chamber reformed. Thirty-four eyes developed cataracts after 6 months postoperatively. Fifteen of these eyes $(44 \cdot 1 \%)$ had shallow/flat anterior chambers (one requiring surgical reformation), and a further $6(17.6 \%)$ had postoperative hypotony (persisting IOP $<10 \mathrm{mmHg}$ ).

Table 9 gives a breakdown of the glaucoma types included in the secondary group with their postsurgical control. The eye with aniridia has undergone previous filtration surgery, including cyclodialysis. The post-trabeculectomy IOP remained uncontrolled despite maximum therapy. One eye with traumatic angle damage required repeat trabeculectomy 2 years later, which failed to normalise the IOP. Trabeculectomy failed to normalise the IOP in a second eye with traumatic angle damage, and retrobulbar alcohol was administered 3 months postoperatively for a painful blind eye.

In the eight eyes with rubeotic glaucoma the condition was secondary to diabetic eye disease in 3 cases and to central retinal vein occlusion in 5 . The intraocular pressure was normalised in only one case (but the visual acuity decreased from counting fingers to no perception of light). Four of the remaining 7 eyes required further procedures to relieve pain (in 2 retrobulbar alcohol injection, 1 cyclocryotherapy, and in the fourth enucleation). The IOP remained elevated in the remaining 3 eyes despite topical and systemic therapy.

Three of the 5 eyes with aphakic glaucoma maintained a normal IOP after trabeculectomy with no

Table 9 Results of trabeculectomy in secondary glaucoma

\begin{tabular}{lllll}
\hline Type & No. & $\begin{array}{l}\text { Control } \\
\text { without }\end{array}$ & $\begin{array}{l}\text { Control } \\
\text { with }\end{array}$ & $\begin{array}{l}\text { Not } \\
\text { controlled }\end{array}$ \\
\hline Uveitis with $2^{\circ}$ glaucoma & 6 & 3 & 2 & 1 \\
Juvenile & 5 & 2 & 0 & 3 \\
Angle recession & 3 & 1 & 0 & 2 \\
Aniridia & 1 & 0 & 0 & 1 \\
Penetrating keratoplasty & 1 & 0 & 0 & 1 \\
\hline
\end{tabular}

complications. One such eye had had previous glaucoma surgery (cyclodialysis). Of the other eyes with aphakic glaucoma both had previous glaucoma surgery (cyclodialysis). In one the IOP remained uncontrolled after trabeculectomy, and the visual acuity with aphakic correction decreased from $6 / 18$ to perception of light (with terminal disc cupping). The other eye maintained a normal IOP after trabeculectomy but became phthisical (visual acuity, no perception of light) within 3 months.

For glaucoma secondary to uveitis the pressure was normalised in $83.0 \%$ of post-trabeculectomy eyes (including those eyes requiring additional topical medication).

Three eyes with juvenile glaucoma failed to achieve a normal IOP postoperatively despite heavy antiglaucoma medication introduced within 2 weeks of operation in all 3 cases.

\section{Discussion}

The intraocular pressure was normalised in $71.9 \%$ of eyes with adult primary glaucoma (i.e., chronic, compound, and acute closed-angle) without the addition of any therapy. $87.8 \%$ of eyes with adult primary glaucoma showed a normalised intraocular pressure if those receiving antiglaucoma medication are included in the analysis. These results are consistent with those reported by many previous authors ${ }^{4891112}$ and are rather higher than those reported by others. ${ }^{13}$ In this series $47.2 \%$ of 34 eyes undergoing the combined procedure had a normalised IOP without additional therapy. A high proportion (38.9\%) required additional medication to achieve IOP control. The percentage uncontrolled $(13.9 \%)$ compares favourably with that in other series $(11.7 \%$ in Jerndal and Lundström ${ }^{6}$ ). The latter authors reported $82.4 \%$ of 17 eyes undergoing the combined procedure to be controlled without additional medication (but $50 \%$ of eyes had pseudoexfoliative glaucoma, which might explain the better IOP control postoperatively).

The lack of success of this procedure in rubeotic and to a less extent secondary glaucoma (apart from glaucoma secondary to uveitis) has been demonstrated $\mathrm{d}^{4}$ and is confirmed in this study.

$71.8 \%$ of 114 eyes requiring additional medication in an attempt to normalise the intraocular pressure do so within the first 6 months of surgery $(57.9 \%$ within the first 3 months). Only $19.3 \%$ of such eyes (5.3\% of total number of eyes in survey) require the institution of such medication after the duration of one year. Thus, once the early postoperative period has passed. the chance of failure becomes quite small. This has also been commented upon by other authors. ${ }^{4}$

Irrespective of the presurgical intraocular pressure the majority of eyes $(76.4 \%)$ return to the physio- 
logical range after surgery. It is worthy of note that $9.9 \%$ of 415 eyes undergoing surgery have a sustained hypotony $(<10 \mathrm{mmHg}$ for $>1$ year $)$, which is at variance with previously reported figures. ${ }^{49} 12$

The intraocular pressure would appear to remain relatively stable with extended follow-up, and in particular, there would appear to be no long-term 'drift or escape.' It is of interest to note that the intraocular pressures in eyes requiring medication, though normalised $(<21 \mathrm{mmHg})$, run at a consistently higher level than in eyes controlled without medication (Fig. 3 ). In eyes requiring medication for control postoperatively the intraocular pressure is lower than when receiving similar medication before operation. This could be due to incomplete or sclerosing fistulisation (as many such eyes have drainage blebs) or represent a more thorough penetration of the ocular medication through the trabeculectomy site.

The incidence of hyphaema of more than 5 days' duration is $6.9 \%$ in this series (excluding rubeotic glaucoma). Only 4 eyes had a persistent hyphaemia ( $>3$ weeks). It is difficult to make meaningful comparisons with other authors as most include all hyphaemas when evaluating results. Ridgway ${ }^{4}$ reported a $15.9 \%$ incidence for chronic simple glaucoma, Portney ${ }^{14} 30 \%$, and Zaidi ${ }^{8} 53 \%$, but all 3 included all hyphaemas in their calculation. Persistent hyphaema is uncommon.

The incidence of cataract after classic fistulising procedures has been calaculated at between 35 and $40 \% .^{15}$ The incidence of cataract in this series producing a decrease in visual acuity of more than 2 Snellen lines is $15.2 \%$, which, while confirming that it is a less harmful procedure to the lens than the classic procedures, nevertheless represents a serious problem. This is higher than reported in some communications (Ridgway ${ }^{4}$ reported $8.7 \%$ incidence of cataract after trabeculectomy in chronic simple glaucoma) but less than others (D'Ermo et al. ${ }^{7}$ reported an incidence of cataract of $35.6 \%$ ). As shown by the latter authors, this may either be an acceleration of pre-existing lens opacities or opacification in previously clear lenses. In 28 eyes $(45 \cdot 2 \%$ of eyes which developed cataract) the change occurred in the first 6 months postoperatively. Seventeen of these eyes $(60.7 \%)$ had a shallow or flat anterior chamber (with reformation of anterior chamber in 2 and resuturing of conjunctival wound in a further 2), and 13 eyes $(46 \cdot 4 \%)$ had ocular hypotony, confirming the observation of D'Ermo et $a l^{7}$ that ocular hypotony may play an important part in the cataract formation. In the 34 eyes in which the cataract developed after 6 months $15(44 \cdot 1 \%)$ had shallow or flat anterior chambers and $6(17.6 \%)$ had ocular hypotony. These results imply that shallowing or abolition of the anterior chamber (with or without ocular hypotony) may disturb lens metabolism sufficiently for opacification to occur. In addition direct trauma to the lens at the time of surgery cannot be excluded as a causative factor.

Clinically one frequently faces a dilemma in the management of cataract developing in a trabeculectomised eye, particularly if unilateral. Removal may convert a stable into an unstable situation with regard to intraocular pressure (with the additional problems encountered in the treatment of aphakic glaucoma). Conventional correction of the aphakia with glasses is not indicated if the fellow eye has normal phakic vision and peripheral field may have been lost due to the glaucomatous process, so benefit may not be derived from this viewpoint. Correction with intraocular implant would be deemed undesirable by most surgeons and contact lens fitment may be difficult because of such things as bleb size, disturbance of pre-corneal tear film, aphakic astigmatism, or lack of dexterity. So, although the trabeculectomy may be successful from the primary consideration of arresting the glaucomatous process, one may produce a nonseeing eye due to advancing cataract (secondary to the procedure) for which treatment from a visual point of view is imperfect. This point has rarely been mentioned in previous communications but represents a fairly frequent problem to the clinician.

The incidence of shallow $(9.2 \%)$ or flat $(3.9 \%)$ anterior chamber (total 13.1\%) in this series is higher than reported by many authors but is similar to that reported by McPherson et al. ${ }^{11}$ (shallow anterior chamber $11.6 \%$, flat anterior chamber $4.5 \%$ ). However, it is significantly less than reported for classical fistulising procedures. For example, Scheie ${ }^{16}$ reported a $41 \%$ incidence of flat chamber lasting more than 3 days in a series of thermal sclerotomies.

Uveal prolapse is a rare complication reported in this series. One eye with a ciliary body prolapse was enucleated because of the risk of sympathetic ophthalmitis. Endophthalmitis after trabeculectomy has not been previously reported in the English ophthalmic literature and case reports with discussion appear in an accompanying communication.

One in 3 eyes (33.9\%) will be affected by one or more of the complications as shown in Table 5. The analysis in Table 7 shows that there is no clear correlation between the incidence of operative and postoperative complications and the control of the intraocular pressure. This finding is rather unexpected.

In summary, it appears from this retrospective survey that, although trabeculectomy represents an important surgical advance (from previous fistulising procedures) in the treatment of glaucoma, it remains a procedure with significant and serious complications. It does, therefore, in the author's opinion, have a doubtful role in the primary management of glaucoma. 
I am indebted to all the consultant staff of the Manchester Royal Eye Hospital for allowing access to patients under their care. I should like to express particular thanks to $\mathrm{Mr}$ A. E. A. Ridgway for his constant help and encouragement during the preparation of this paper.

\section{References}

1 Cairns TE. Trabeculectomy-preliminary report of a new method. Am J Ophthalmol 1968; 66: 673-9.

2 Watson P. Trabeculectomy-a modified ab externo technique Ann Ophthalmol 1970; 2: 199-205.

3 Ridgway AEA. Rubinstein K. Smith VH. Trabeculectomy-a study of 86 cases. Br J Ophthalmol 1972; 56: 511-6.

4 Ridgway AEA. Trabeculectomy-a follow-up study. $\mathrm{Br} J$ Ophthalmol 1974; 58: 680-6.

5 Watson PG. Barnett F. Effectiveness of trabeculectomy in glaucoma. Am J Ophthalmol 1975; 79: 831-45.

6 Jerndal T, Lundström M. 330 Trabeculectomies-a follow-up study through $1 / 2-3$ years. Acta Ophthalmol $(K b h)$ 1977; 55: $52-62$.

7 D'Ermo F. Bonomi L. Duro D. A critical analysis of the longterm results of trabeculectomy. Am J Ophthalmol 1979; 88: 829-35.
8 Zaidi AA. Trabeculectomy: a review and a 4 year follow up. $\mathrm{Br} J$ Ophthalmol 1980; 64: 436-9.

9 Thyer HW, Wilson P. Trabeculectomy. Br J Ophthalmol 1972; 56: $37-40$.

10 Spencer WH. Histological evaluation of microsurgical glaucoma techniques. Trans Am Acad Ophthalmol Otolaryngol 1972; 76: 389-97.

11 McPherson SD, Cline WJ, McGurdy D. Recent advances in glaucoma surgery trabeculotomy and trabeculectomy. Ann Ophthalmol 1977; 9: 91-6.

12 Loewenthal LM. Trabeculectomy as treatment for glaucoma: a preliminary report. Ann Ophthalmol 1977; 9: 1179-86.

13 Schwartz AL, Anderson DR. Trabecular surgery. Arch Ophthalmol 1974; 92: 134-8.

14 Portney GL. Trabeculectomy and post-operative hypertension in secondary angle closure glaucoma. Am J Ophthalmol 1977; 84: 145-9.

15 Chauvaud D, Caly-Fressinet C. Pouliquen Y, Offret G. Opacification of the crystalline lens after trabeculectomy. Arch Ophthalmol 1976; 36: 379-86.

16 Scheie H. Filtering operations for glaucoma. Am J Ophthalmol 1963; 53: 571-90. 